NBER WORKING PAPER SERIES

IS THERE A LAG?

Bronwyn H. Hall

Zvi Griliches

Jerry A. Hausman

Working Paper No. 1454

NATIONAL BUREAU OF ECONOMIC RESEARCH

1050 Massachusetts Avenue

Cambridge, MA 02138

September 1984

The research reported here is part of the NBER's research program in Productivity and project in Productivity (World Economy). Any opinions expressed are those of the authors and not those of the National Bureau of Economic Research. 
NBER Working Paper \#1454

September 1984

\section{Is There a Lag?}

\section{AB S TRACT}

This paper ertends earlier work on the RQD to patents relationship (Pakes-Griliches 1980, and Hausman, Ha11, and Griliches, 1984) to a larger hot shorter panel of firms. The focus of the paper is on solving a number of econometric problems associated with the discreteness of the dependent variable and the shortioss of the panel in the time dimension. We compare weighted nonlinear least squares as well as Poisson-type models as solutions to the former problem. In attempting to estimate a lag structure on RQD in the absence of a sufficiont history of the variable, we take two approaches: first, wo use the conditional version of the negative binomial model, and second, we estimate the RaD variable itself as a low order stochastic process and use this information to control for unobserved R\&D. R\&D itself turns out to be fairly we11 approrimated by a random walk. Neither approach yields strong evidence of a long 1ag. The available samplo, though numerically large, tarns out not to be particularily informative on this question. It does reconfirm, however, a significant effect of RlD on patenting (with most of it occnring in the first year) and the presence of rather wide and semi-permanent differences among firms in their patenting policios.

Bronwyn H. Ha11

National Bureau of

Economic Research 204 Junipero Serra B1vd. Palo A1to, CA 94305
Zvi Griliches Nationa 1 Bureau of Economic Research 1050 Massachusetts Ave. Cambridge, MA 02138
Jerry A. Hausman

Department of Economic M. I. T. E52-271A

Cambridge, MA 02139 
Bronwyn H. Hall, Zvi Griliches, and Jerry A. Hausman

This paper analyzes the relationship between patenting and research and development activity at the firm level by the U. S. manufacturing sector during the 1970's. Previous work by Pakes and Griliches (1980), which looked at a subset of the firms considered here, was the first attempt to use the patenting and R\&D behavior of firms over time both to control for individaal firm effects and to try to learn something about lags in the productivity of RED. The present study extends their sample to 1979 and covers almost all of the firms doing appreciable amounts of RQD in the manufactoring sector. In attempting to characterize the lag structore of the patents-RaD relationship, number of econometric problems arising from the panel nature of the data and from the measurement of the dependent variable have to be solved or at loast considered in interpreting the results.

The basic model onderlying this analysis has been described elsewhere (Pakes and Griliches 1980. Hausman, Ha11, and Griliches 1984) and will only be sketched here. The annual research and development expenditares of a firm are considered to be investments which add to a firm's stock of knowledge. This stock of knowledge is depreciating over time so that the contribution of older RaD investment becomes less valuable as time passes. The aim of the study is to use patent applications in any given year as an indicator of the "value" of the underlying stock of knowledge, and to infer from the lag distribution on past Rob something about gestation lags in 
knowledge production. It is important to note at the outset that there are difficulies with this approach: the first is that patents are not the only output of RED - they measure only a fraction of this output, and the fraction may vary considerably over industry and possibly also over time. Controlling for differences in the firms' propensity to patent (conditional estimation) as well as including an overalleffect for each year are partial answers to this. A second and related problem with the existing data is that most of the information on the question will come from relative changes in the two variables over time within the firm; if these changes are contaminated by measurement error or they are very sma11, the lag structure will be extremely difficult to discern.

A third problem has to do with the oconomic value of the patents themselves. Researchers such as Mansfield (1977) and Taylor and Silberston (1973) have suggested that the existence of the patent system may be a relatively unimportant factor in the research and development strategy of some firms. There is also a growing body of evidence (Grabowsi 1983, Pakes 1984, Schankerman and Pakes 1984) showing that a large fraction of patents granted are "worthless" or become worthless in a short period of time. This paper has very little to say on this range of topics; we observe the fact that firms do take out patents which are related to the outpat of their research and development laboratories (and other activities of the firm in the RotD area) and that therefore, patents can be used as an indicator of this activity in the aggregate even though the information conveyed by an individual patent may be very small.

In discussing an earlier version of this paper, Stoneman (1983) argued strongly that patents are an input to the R\&D procoss rather than an outpat. That is, the patent application occurs at an early point in the development process and most of the expenditures that would be associated 
with it occur after the appication is made. With this data we are in a position to investigate this question of timing, and find that the evidence for it is relatively weak, at least in aggregate firm behavior. The strongest thing one can say is that R\&D and patents appear to be dominated by a contemporaneous relationship, rather than leads or lags.

The earlier work in this area also found a strong contemporaneous effect of R\&D on patents but was inconclusive as to whether there was a significant lagged effect. Pakes and Griliches, osing the standard fixed effects mode1, found evidence of a lag trancation effect in the distributed lag of patents on R\&D. That is, when they controlled for permanent differences across firms in the propensity to patent, the estimated coefficient on the last lag of R\&D which they considered (RQD expenditures of four years prior) was significantly higher than the coefficients of more recent R\&D. Hausman, Ha11, and Griliches ased a different fanctional form (which took the discreteness of the patent data explicitiy into accont) and found similar results for the random (uncorrelated) effects model but not in their conditional fired effects version. When they conditioned their estimates on the total number of patents received during the whole period, no coefficients except for the contemporaneous Red variable were statistically significant either in the Poisson or negative binomial version.

These previous studies both used samples of about 120 firms with seven to eight years of patent data and twelve to thirteen years of R\&D data. For the current study, although we have about fourteen years of patent data from 1966 to 1979, we have only eight years of RHD data for about 650 firms, with an additional two years (1970 and 1971) for half the firms. This fact constrains our ability to look for very long lag effects, 
especially since we cannot distinguish easily between permanent differences across firms in the propensity to patent and effects due to the unobserved past RQD history. We discuss this issue at greater length in the body of the paper.

The other problem we have to deal with is the specification of the error term in our model. The difficulty arises from two somewhat related causes: the presence of a large number of zeroes in our dependent variable, the number of patents applied for by a firm in a particular year, and the large size range of the firms in our sample. A previous paper (Bound et al 1984) which analyzed a large cross section sample, including the firms under consideration here, demonstrated that estimates were quite sensitive to the specification of the distribution of the error term. Since most of the estimators used were consistent, this can be construed as informal evidence of misspecification of the underlying model, possibly due to nonlinearity in the relationship of $10 g$ patents to $\log R E D$ or to heteroskedasticity which is size-related. We have taken two approaches in obtaining our estimates in this paper: the first uses a nonlinear least squares specification with additive errors; for these estimates we are able to obtain robust standard errors whichare correct in the presence of arbitrary heteroskedasticity, including year-to-year correlation within firms. For this version of the model however, we are unable to obtain conditional estimates, due to its intrinsic nonlinearity and the shortness of our pane1. The second approach uses an explicit stochastic specification for the patents variable, that it follows a Poisson or negative binomial distribution, whichenables us to obtain conditional estimates of the slope parameters, but at the price of a distributional assumption which may not hold.

The plan of this paper is the following: first we discuss the 
derivation of our dataset and look at the properties of our independent variable. RaD expenditures. Then we present some estimates of the basic patents-Rob relationship. followed by a discussion of the biases which may be present in the cross section estimation of this relationship. Finally we present conditional estimates of our model in an attempt to control for some of these biases and we conclude with a brief discussion of what we can learn from these data. 


\section{Data}

The data we use are an extract from a larger and longer panel of firms in 0. S. manufacturing drawn from the Compustat (Standard and Poor 1980). This dataset was assembled and combined with patent data form the office of Technology Assessment and Forecasting at the NBER and is described in Bound et a 1 (1984) and Cummins, Ha11, and Laderman (1982). The original universe from which our sample comes consisted of approximately 2700 firms in the manufacturing sector in 1976, and included almost all of the firms which report RQD expenditures to the Bureau of Census-NSF RED survey.

Our sample of firms was chosen from this aniverse by requiring that data on sales, gross capital, market value (value of common stock), and $R$ D be available for all years from 1972 through 1979 with no 1 arge jumps during that period. A jump is defined as an increase in capital stock or employment of more than 100 per cent or a decrease of more than 50 per cent. This test was not applied unless the change in employment was greater than 500 employees or the change in capital stock was greater than two million dollars. We also removed six firms which had abnorma11y small R D values ( 1 ess than $\$ 10,000$ ) in one of the years. The number of firms remaining in the sample after these cuts was 642, with a size distribution heavily tilted toward the larger firms in our original aniverse. Table 1 shows the selectivity of this sample with respect to size and indicates that although we have only a quarter of our original sample of firms, most of those lost were either smaller or were not $R$ D doing (and reporting) firms. Our coverage of the larger $R$ D firms is almost complete, and our sample includes 90 per cent of the RAD dollars expended by the manufacturing sector in 1976 .

Table 2 exhibits the characteristics of our remaining sample of firms. 
both the 642 firms with $R$ between 72 and 79 and a subset of firms with a longer R D history back to 1970. Quantiles are shown in order to give some indication of the skewness of the data: for example, median sales for this sample in 1976 were 182 million dollars, while mean sales were 1.06 billion dollars. The subset of firms with a longer RED history consists of somewhat larger firms and is more heavily tilted toward the scientific sector. Even for this sample of relatively ReD-intensive firms, we find that over 20 per cent of the firms did not apply for patents in 1976 and that more than half applied for less than five. This confirms our impression that the patents variable in these data must be treated in a way which correctly reflects its relative imprecision at small values. Previous experience with estimation of the patents equation in the cross section (Bound et al 1984) has shown os that slope coefficient estimates may not be robust to changes in the way in which we specify the error in the equation (and the weighting which is implied by such specification).

In the later sections of this paper we look at this question again in an effort both to. draw some robast conclusions from the data and to understand the reasons for the anstable coefficients. However, first we take a closer look at the process generating onr independent variable. Reb, since the way it evolves has important implications for our ability to identify the trae coefficients in the presence of 1 ag truncation and firm effects.

To study the stochastic process for ReD, we ase a procedure due to Macardy (1983) for computing the sample autocorrelation and partial atocorrelation functions. Basical1y, this method treats each firm as an independent draw on a time series process, so that we have 642 observations on eachatocorrelation and partial antocorrelation. Since these can be estimated for each year, it is not necessary to impose covariance 
stationarity. This model allows each firm to have its own mean, but assumes that the within firm variance is the same across firms, which is not an unreasonable assumption for the logarithmic form of our data. We can test for stationarity of the variances across time, and in our data we find $F(7,5128)=6.3$ which is significant at the conventional five per cent level, but insignificant using the large sample critical values due to Leamer (1978). Accordingly, we impose stationarity in order to compute the autocorrelation and partial antocorrelation functions.

The results are shown in Table 3: the autocorrelations are all above 95, and shive a very small decrease at longer lags, while the partial atocorrelations are essentially zero after the second 1 ag. with the second 1 ag equal to $.048(.034)$. This is strong evidence for a low order AR process; in fact, it is difficult to reject a random walk, although there is a hint of a small positive coefficient on the second lag and a first lag coefficient of slightly less than one. In order to check this result, we compute the AR regression itself and display the results in the second part of Table 3. The standard errors shown are heteroskedastic-consistent estimates, although they are in fact almost the same as conventional estimates, which is evidence that the assumption of constant within-firm variance is not a bad one. The basic result is that the AR2 specification can be accepted at conventional significance levels, and that the process is in fact very close to a random walk.

The last two columns of this table provides a partial answer to the question of whether patents can be viewed as an input to the ReD process in this data. We use a simple version of aranger causality test: with two lags of RED used to predict the current lovel of RED, we include contemporaneous and lagged 108 patents in the regression to see if they help in predicting RED in the presence of its past history. The coefficient on contemporaneous $10 \mathrm{~g}$ patents is significant (t=3.1). but 


\begin{abstract}
lagged patents are of no help in predicting future RaD, even if we leave contemporanoous patents out of the equation (1ast column). We tentatively conclude that there may be simaltaneous movements in patents and RaD, but there is little ovidence that past succossin patenting leads to an increase in a firm's future R\&D program above and beyond that implied by its R\&D history. 1 We should qualify this result by noting that there is a considerably lower signal to noise ratio in the patents variable than in the RaD variable, both because of the skewness in patent values mentioned earlier and because it is intrinsically an integer variable. This has been well documented by Pakes and Griliches (1980) and Pakes (1984). Since RaD is highly correlated over time, it will be difficult to discern the independent contribution of patents to the R\&D program in the presence of this noise.
\end{abstract}


In earlier work with the 1976 cross section of these firms. Bound et al found that estimates of the elasticity of patenting with respect to RQD at the average RQD in the sample varied from 0.35 to 2 , depending on the choice of specification: log linear, Poisson, negative binomial, or nonlinear least squares. This difference was greatly attenuated when the firms were divided into two groups, those with $R$ D budgets larger than two million dollars and those with smaller $R$ D budgets. In the present paper, the problem is not as severe since our sample is more heavily weighted toward the firms in the larger group (approrimately 50 per cent have $R$ D greater than two million, rather than 20 per cent), but it still persists and affects onr estimates of the lag distribution.

In Table 4, we look at the differences in estimates of our basic model which are implied by differing specifications of the error structure. The mode 1 is

$$
E\left(p_{i t} \mid R_{i t}, R_{i, t-1} \cdots \ldots s_{i}, t\right)=\exp \left[\int_{\tau}\left(\beta_{\tau} \log _{i, t-\tau}\right)+\delta^{\prime} s_{i}+a_{t}\right]
$$

where $s_{i}$ are the observed firm characteristics (size, as measured by the $\log$ of gross plant in 1972, and a dummy for the scientific sector). Our sample is the 642 firms estimated over the years 1975 to 1979 so that we can include three lags on RtD, Which yields a total of 3210 observations on the dependent variable, patents. The first column shows the nonlinear least squares estimates of the parameters, which are obtained by assuming an additive and homoskedastic error in equation (1). These estimates are consistent for the underlying coefficients, provided the model is correctly specified. The standard errors shown are robust to heteroskedasticity of the distarbances; they are computed using the formulas due to Eicker-White- 
Chamberlain, and allow both for differing variances across firms and arbitrary serial correlation over time within firms.

The next two columns of Table 4 give the results of estimating the Posson and negative binomial versions of our models. The advantage of these models is that they take into account the non-negativity and discreteness of our data. Moreover, in the next section of this paper we will see that the conditional versions of these models allow us to estimate a fixed effects mode1, something that we cannot do easily with the nonlinear least squares version of the model. On the other hand, these models require us to be explicit about the exact form of the distribution from which the disturbance is drawn, and may produce inconsistent estimates if the distribution is not correct (Gourieroux, Montfort, and Trognon 1984).

The Poisson and negative binomial models were described in detail in our earlier paper (Hausman, Ha11, and Griliches 1984) and we sha11 summarize only their main features here. The log likelihood function for the Poisson mode1 is given by

(2) $\log L=\sum_{i=1}^{N} \sum_{t=1}^{T}\left[y_{i t}{ }^{1}-e^{x_{i t} \beta}+y_{i t} x_{i t}^{\beta}\right]$

where $y_{i t}$ is the observed number of patent application for a firm in a yer and the $X_{i t}$ are the independent variables, RaD and firm characteristics. Estimates obtained with this model differ from the nonlinear least squares estimates primarily by the weighting scheme used. The NLS estimates are unweighted, implicitly weighting the numerically larger deviations of the larger firms more than those of the small firms. The Poisson model assumes that the variance of the disturbances is proportional to the expected value 
of the patents and weights the observations accordingly. The negative binomial model generalizes the Poisson model by allowing for an additional source of variance above that due to pure sampling error. The logarithm of the 1 ikelihood for this model is

(3) $\begin{aligned} \log L & =\sum_{i=1}^{N} \sum_{t=1}^{T} \log \Gamma\left(\lambda_{i t}+y_{i t}\right)-\log \Gamma\left(\lambda_{i t}\right) \\ & -\log \Gamma\left(y_{i t}+1\right)+\lambda_{i t} \log (\delta)-\left(\lambda_{i t}+y_{i t}\right) \log (1+\delta)\end{aligned}$

where $\lambda_{i t}=\exp \left(x_{i t} \beta\right)$ and $\delta$ is the variance parameter (Vy ${ }_{i t}=$ $\left.\exp \left(x_{i t} \beta\right)(1+\delta) / \delta\right)$. We estimate both of these models by standard maximum likelibood techniques.

Fina11y, in the last colnmn of Table 4, we show estimates computed using the quasi-generalized pseudo maximum likelibood (QGPML) method of Gonrieroux, Montfort and Trognon (1984, henceforth referred to as GMT). This estimator is based on the following idea: suppressing the t subscript for the moment, we assume that the trae model for patents is

$$
y_{i}=\exp \left[x_{i} \beta+e_{i}\right]
$$

where exp(e $)$ is a multiplicative distarbance drawn from an unspecified distribution. If a constant term is incladed as one of the $X^{\prime} s$ we can assume $E\left[\exp \left(e_{i}\right]=1\right.$ and $V\left[\exp \left(e_{i}\right)\right]=\eta^{2}$. Then the expected number of patent applications conditional on the $X^{\prime}$ 's is exp( $\left.x_{i} \beta\right)$ and the variance is $\exp \left(x_{i} \beta\right)+\eta^{2} \exp \left(2 x_{i} \beta\right)$. That is, the variance equals the mean plus a parameter times the mean squared. We can obtain consistent estimates of the parameters $\beta$ for this model using nonlinear least sqaares, use these to estimate $\eta^{2}$. form a vector of GLS weights which are proportional to the variance of the dependent variable: 


$$
w_{i}=\hat{y}_{i}+\hat{\eta}^{2} \hat{y}_{i}^{2}
$$

and use these weights to obtain more efficient estimates of the $\beta$ 's. The formula for the variance of these estimates is given in GMT, and is a special case of the Eicker-White-Chamberlain formula with known weights.

Since all of these models differ only by their distributional assumptions and not by specification of the expected value, they should all yield roughly the same results unless the basic specification of the equation is wrong. In fact, it can be shown (see GMT) that both the NLS estimates and the Poisson estimates of the parameters are consistent if we have correctly specified the expectation in (1) and the true conditional distribution satisfies certain reguarity conditions given in their article. Because the estimators make different assumptions about the error structure they do yield different estimates of the standard errors, even in the case of similar coefficients. In this respect, the nonlinear least squares estimates, weighted or unweighted, are the most robust, since we have computed standard errors which allow for anknown heteroskedasticity. It can be seen from the table that in return formaking a relatively mild assumption about the form of the variance (that it is increasing in the mean and mean squared), we obtain a considerable increase in the precision of our estimates (compare columns 1 and 4 ).

In Table 4 we see that the results of using the four different estimators on this dataset are qualitatively the same, although there is a substantial increase in the coefficient on contemporaneous ReD as we move from nonlinear least squares to weighted nonlinear least squares (GMT). Since the estimators in columns 1,2 , and 4 are consistent if we have the correct mode1, but are estimated with different weighting schemes. ${ }^{2}$ one possible explanation of the differences in coefficients, particularily the 
sum, may be that the relationship between patents and RaD is not stable across the firms in our sample. An indication that this is a problem is provided by the substantial increase in standard errors when we use robust est imates.

The dimension along which the weighting schemes vary is basically related to the size of the firms in the sample. Therefore we partitioned them into roughly equal groups: thosewith assets (book value of net plant) less than 25 million dollars in 1972 and those with assets greater than 25 million. We then estimated the same model as column (4) of Table 4 on the two groups separately. Although the total RaD effect was the same for the two groups (.66), it was distributed differently across the lags: $0.31, .11, .14, .11$ for the sma 11 er firms and $.32, .01, .02, .31$ for the larger firms. This suggests that the waintained hypothesis of a roughy constant lag structure across the firms may be one reason for the apprent instability of our results. Unfortunately it is not possible with this dataset to construct a more detailed behavioral model which is capable of accounting for different lag structures across firms. We can only suggest areas for future investigation. 


\section{Correlated Effocts or Lag Trancation Bias?}

In obtaining the results shown in Table 4, there was no attempt to control for permanent differences in the propensity to patent across firms, except for the firm size variable and a dumy for the scientific sector. We expect that these differences may bias our estimate of the RQD coefficients if they are correlated with the RaD variables. All of the estimates, except possibly those for the smaller firms, exhibited evidence of a u-shaped lag structure, with the first and last coefficients being larger than those in the middle. The large coefficient ou the last lag conld be dae to the correlation of the last RaD variable with earlier leftout R\&D, bat it turns out that ander reasonable assumptions on the RQD process itself, it could also be caused by (correlated) fired effects.

Assume that the log deflated RqD variable itself follows a first order antoregressive process:

$$
R_{t}=\gamma R_{t}+e_{t} \quad e_{t} \text { white noise process }
$$

Then the actocorrelation coefficients for the ReD process are (1, $\gamma, \gamma^{2}$ $\ldots \ldots)$ and the partial autocorrelation coefficients are $(\gamma, 0,0, \ldots)$. We have seen that just such a pattern is consistent with onr RoD data. If we maintain the hypothesis that RqD follows an AR1 process, we can compute the bias formula for the coefficients on RaD in the presence of two types of omitted variable: 1) pre-sample RQD, which is correlated with in-sample R\&D in a geometrical1y decaying way, and 2) a permanent fixed effect which has the same correlation with R\&D in all periods. In the first case, the bias formula for $\beta=\left(\beta_{0}, \beta_{1}, \ldots, \beta_{k}\right)$, where there are 1 lags in the regression, is 
(4) $p$ im $\beta=\beta+\frac{\beta_{k+1}}{\sigma_{x}^{2}\left(1-\gamma^{2}\right)}$

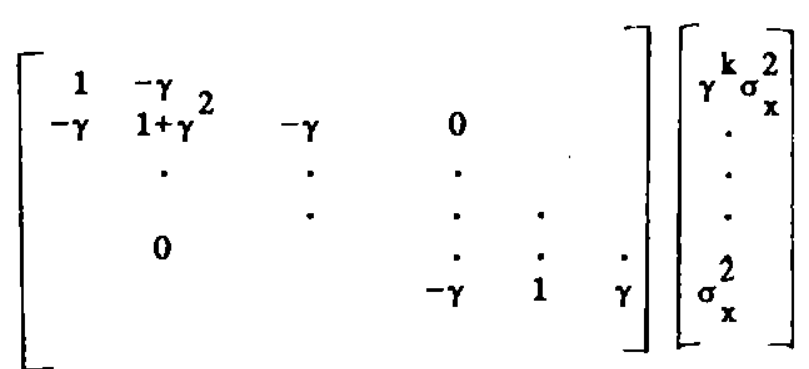

$$
=\beta+\beta_{k+1}\left[\begin{array}{c}
0 \\
\cdot \\
\cdot \\
0 \\
\gamma
\end{array}\right]
$$

If only the most recent pre-sample R\&D belongs in the equation, the last coefficient is biased upward by $\beta_{k+1} \gamma$ where $\beta_{k+1}$ is the coefficient on the R\&D one period before the sample begins. In general, the bias on the last coefficient will be equal to $\sum \beta_{k+\tau} \gamma^{\tau}$. In our case, since $\gamma$ is close to unity, we expect the last coefficient to be roughly equal to the sum of the 1 ag coefficients for all the earlier RED plus its own coefficient.

On the other hand, if we assume a fired effect $\mu_{i}$ for each firm has been omitted, we obtain the formula

(5) $p$ im $\beta=\beta+\frac{1}{\sigma_{x}^{2}\left(1-\gamma^{2}\right)}$

$$
\left[\begin{array}{cccccc}
1 & -\gamma & & & & \\
-\gamma & 1+\gamma^{2} & -\gamma & & 0 \\
& \cdot & \cdot & \cdot & & \\
& 0 & & & \cdot & \\
& & & & -\gamma & 1
\end{array}\right]\left[\begin{array}{c}
\eta \sigma_{x} \sigma_{\mu} \\
\dot{\cdot} \\
\dot{\gamma}_{x} \sigma_{\mu}
\end{array}\right]
$$

$$
=\beta+\frac{n \sigma \mu}{(1+\gamma) \sigma_{\times}}\left[\begin{array}{c}
1 \\
1-\gamma \\
\dot{ } \\
1-\gamma \\
1
\end{array}\right]
$$

where $\eta$ is the correlation of the fixed effect with ReD and $\sigma \mu^{2}$ is the variance of the effect. The implication is that we would see a large 
positive bias in the first and last coefficient and a smaller one in the middle coefficients. If $\gamma$ is close to one, as it appeas to be in our data, the bias for coefficients $\beta_{2} \ldots \ldots \beta_{k-1}$ would be negligible.

To explore this idea further, we use a longer sample of firms which have RAD data available back to 1970. This leaves us with 346 firms, slightly more than half of our original sample, and somewhat more heavily weighted towards larger firms. For this sample, we obtain estimates for a model with five lags on R\&D (shown in Table 5). For comparison, estimates of the original model (with three lags) on this new sample are also shown. It appeas from these results that some of the effect we observed in the 1 ast lag was indeed due to truncation (note how the coefficient on $R_{-3}$ in column 1 is spread between $R_{-3}, R_{-4}$ and $R_{-5}$ in column 2); if we pash the idea further by estimating with seven lags on the last three years of data (1977 through 1979), the loading on the last lag seems to have disappeared. However, we have also pushed the data beyond the point where it will yield meaningfol results, since significant instability in the R\&D coefficients for adjacent years is now evident. The tentative conclosion is that there is anlikely to be a substantial effect of RQD more than seven years old on the patent activity of firms in the manufacturing sector.

To examine the other alternative, a fired effects explanation of the ashaped lag distribution, we hypothesize a differing propensity to patent for each firm which is (possibly) correlated with its Res activity. The reasoning in this section suggests that estimates conditional on the permanent patenting propensity of the firm should reduce both the first and last lag coefficient if we have correlated effects and only the last one if the problem is lag truncation (and the lag trancation is relatively constant from year to year). This leads us to look at models which are conditional on the permanent RQD behavior of firms in the next section. 


\section{Conditional Estimates}

We take two different approaches to obtaining conditional estimates for our mode1: the first includes all observed values of RED (for a firm) in each equation with the coefficients constrained to be equal across the different years. This is an attempt to control for fixed effects which may be correlated with our R\&D variables, since we cannot simply estimate the effects due to the shortness of our panel and the noninearity of the mode1. The second approach imposes a specific distribution on the error term, namely the negative binomial, allowing os to derive an estimator which is conditional on the total number of patents applied for by the firm in all the observed years.

This second approach was described in our earlier paper (Hausman, Hall, and Griliches 1984): by conditioning on the total number of patents applied for by the firm, it essentially allows for a different intercept for each firm. Dae to the maltiplicative natare of the error in this model, this translates into a diferent variance for each firm, so that the conditional model estimates an overall variance parameter, but not the individual intercepts or variances. The $\log 1$ ikelihood for this model is

$$
\begin{aligned}
\log L & =\sum_{i t} \sum_{t} \log \Gamma\left(\lambda_{i t}+y_{i t}\right)-\log \Gamma\left(\lambda_{i t}\right)-\log \Gamma\left(y_{i t}+1\right) \\
& +\log \Gamma\left(\sum_{t} \lambda_{i t}\right)+\log \Gamma\left(\sum_{t} y_{i t}+1\right)-\log \Gamma\left(\sum_{t} \lambda_{i t}+\sum_{t} y_{i t}\right)
\end{aligned}
$$

Table 6 gives the results of estimates obtained in both ways for both of our samples of firms. The first tro columns are estimates of the conditional negative binomial model, while the last two are estimated osing weighted nonlinear least squares on equation (1), where the firmeffect ${ }_{i}$ 
includes a 11 the RQD variables in all years, but with coefficients $\delta$ constrained to be the same across the years. These two methods of estimation are both compronises of a different sort: the negative binomial version allows for an arbitrary firmeffect while making a specific distributional assumption while the GMT version controls for a firm effect correlated with RQD in a particular way (1inear in the exponential function) but does not impose a distribution on the error term. It is therefore reasuring that there are not huge differences between them.

The basic result is that none of the coefficients are significant except those on current RQD, although the total effect of the lagged RQD does seem to add about .05 to the coefficient on the sum. It makes very little difference whether we look at the 642 firm sample or the sample of 346 firms which has a longer R\&D history. From the fact that the coefficient on contemporaneous RQD hardly changes from the unconditional estimates, while that on the last RED goes to zero we conclude that wost of what we have removed by conditioning is the RAD prior to our longest 1ag. This confirms the result of Table 5 where we saw a considerable smearing of the lag coefficients when we used a longer lag in the unconditional estimates. However, the coefficients are fairly unstable and the standard errors are large, so the most we can say is that there appears to be a fairly strong contemporaneous effect, even when firm effects are controlled for. Evidence for a contribution of lagged RQD to current patenting activity is of the order of about 0.05 in the conditional estimates and possibly 1 arger in the unconditional.

Using an idea in Pakes and Griliches (1984), we can try to estimate more lags in this equation by assuming that RQD follows a low order AR process, in this case AR1. Since this implies a correlation only between the last included RQD and the presample RED, the estimates of all coefficients 
except the last will be unbiased by the omission of earlier RaD. Accordingly, we leave the last coefficient free in each year of the equation, which allows us to estimate six lags in the 1972-1979 sample and eight lags in the 1970-1979 sample. The precision of the estimates declines with the length of the lag since we have fewer and fewer observations for the longer lags (1agsix in the 1972-1979 sample is estimated only from the 1979 equation, for example). However, this constraint allows us to use all but one of the years of data on patents for each sample of firms, so that we have seven years in the 642 firms sample and nine in the 346 firms sample.

We show these results in Table 7; they are essentially the same as the conditional estimates in Table 6. We also estimated this version of the model including firm effects correlated with RED; these turned out to be insignificant $\left(x^{2}(7)=3.9\right.$ for the first column and $x^{2}(9)=11.2$ for the second), although the model in this form is highly collinear so that it is difficult to draw firm conclusions.

The basic message of the results in this section is that permanent differences across firms in the propensity to patent do not appear to bias our estimates of the distributed lag relationship between patenting and RED, except insofar as they are related to the presample history of R\&D. The results of the previous section suggested that this bias, if it existed, would appear of equal magnitude in the first and last lag coefficients of RED. This does not seem to be the case; what bias there is seems only to affect the last 1 ag, and is eliminated by modeling the presample RaD process itself. This does not imply that there are no differences in the propensity to patent across firms: the size variable and the scientific sector dumy are still significant in the final version 
of the model. Nor does it imply that all the differences are uncorrelated with RQD, but only that the correlation which is observed can be successfully explained by controlling for the part of the RQD history which we do not observe. 


\section{Conclusion}

What do we conclude from this lengthy exploration of a basically simple mode1?. First, there does seem to be a rather strong contemporaneous relationship between R\&D expenditures and patenting, which does not disappear when we control for the size of the firm, its permanent patenting policy, or even the effects of its RqD history. The remaining elasticity appears to be about. 3 with a fairly large standard error. Second, the contribution of the observed RQD history to the current year's patent applications is quite sma11, on the order of .05. Third, the contribution of the unobserved or presample RQD appears to be large, about .25, and is a possible explanation of the existence of the observed differences across the firms in the propensity to patent.

One of the most interesting results in this paper has nothing to say about patenting, although it provides one reason why we have diffculty measuring the relationship within firm over time: the characterization of the pattern of R\&D investment within a firm as essentially a random walk with a relatively low error variance. In other words, Rad budgets over this short horizon ( 8 gears) are roughly constant or growing slightly (in constant dollars) and therefore it is difficult to imagine that they are very sensitive to patenting success or vice versa.

Finally, it is difficult to give a clear cut answer to the question this paper was originally designed to answer: is there a significant longrun effect of successful R\&D investment for which patents can serve as an indicator? The evidence here indicates the longrun level of R\&D can be quite important, but the result is predicated on inference about the unobserved part of the RED process. There is very little direct evidence of anything but simultaneity in the year-to-year movements of patents and 
RQD. This finding suggests another way of looking at the process: in large industrial firms the fraction of RED expenditures devoted to development rather than basic or applied research tends to be well over fifty per cent (NSF 1982). It seems reasonable to suppose that successful research leads both to a patent application and to a committment of funds for development. A detailed investigation of this timing is beyond the scope of annul data, but the strongevidence of simultaneity in patents and RAD in our data conforms very well to this picture.

We should not close this paper on the usual note of the failure of the data to live up to our econometric expertise. Even though we have not been able to elucidate the RED to patents lag structure better, our overall findings are quite interesting, showing a persistent significant contemporaneous relationship of $R \& D$ and patenting and rather wide and semipermanent differences across firms in their patenting and R\&D policies. The later finding provides the challenge for further research in a different style: trying to understand how and why fins differ in their responses to the technological environment they find themselves in. 
Tab10 1

Selection of the Sample of Firms

\begin{tabular}{|c|c|c|c|c|c|}
\hline \multirow[b]{2}{*}{ Sales } & \multicolumn{2}{|c|}{ Number in } & \multirow[b]{2}{*}{$\begin{array}{l}\text { Number in } \\
\text { Sample }\end{array}$} & \multicolumn{2}{|c|}{ Coverage } \\
\hline & A11 & $\begin{array}{l}\text { Sect 10n } \\
\text { RED }>0\end{array}$ & & A11 & $\begin{array}{l}\text { rage } \\
\text { RQD }>0\end{array}$ \\
\hline less than $\$ 1 M$ & 73 & 33 & 1 & .014 & .03 \\
\hline$\$ 1 M-10 M$ & 548 & 293 & 17 & .031 & .06 \\
\hline$\$ 10 \mathrm{M}-100 \mathrm{M}$ & 1102 & 579 & 224 & .20 & .39 \\
\hline$\$ 100 M-1 B$ & 669 & 415 & 259 & .39 & .62 \\
\hline$\$ 1 B-10 B$ & 204 & 167 & 131 & .64 & .78 \\
\hline more than $\$ 10 B$ & 12 & 11 & 10 & .83 & .91 \\
\hline Total & 2608 & 1498 & 642 & .25 & .43 \\
\hline
\end{tabular}

1976 R D Expenditures

in 1976 dollars

76 Cross section Sample Coverage

\begin{tabular}{lrrr} 
less than \$1M & 3.0 & 0.9 & .30 \\
$\$ 1 M-10 M$ & 65.3 & 4.7 & .07 \\
$\$ 10 M-\$ 100 M$ & 525.2 & 243.1 & .46 \\
$\$ 100 M-1 B$ & 2354.1 & 1790.7 & .76 \\
$\$ 1 B-\$ 10 B$ & 7830.6 & 7224.1 & .92 \\
more than \$10B & 4593.2 & 4529.2 & .99 \\
Tota 1 & $15,371.3$ & 13.793 .0 & .90 \\
\hline
\end{tabular}


Table 2

Key Variables in 1976

\begin{tabular}{|c|c|c|c|c|c|c|}
\hline \multirow[b]{2}{*}{ Variable } & \multirow[b]{2}{*}{ Min } & \multicolumn{3}{|c|}{642 Firms } & \multicolumn{2}{|c|}{346 Firms } \\
\hline & & 1st $Q$ & Median & $3 \pi d Q$ & $\operatorname{Max}$ & Median \\
\hline Sales $(\$ M)$ & .6 & 57 & 182 & 760 & 49,000 & 263 \\
\hline$R \& D(\$ M)$ & .02 & .73 & 2.3 & 11.0 & 1,256 & 3.8 \\
\hline Patents & 0 & 1 & 3 & 18 & 831 & 5 \\
\hline \multicolumn{7}{|l|}{ Fraction with } \\
\hline zero potent & & & .21 & & & .17 \\
\hline \multicolumn{7}{|l|}{ Fraction in } \\
\hline scientific & sector & & .37 & & & .42 \\
\hline
\end{tabular}

Notes to Table 2

All dollars are millions of 1976 dollars.

The scientific sector is defined as firms in the drag, compoter, scientific instrument, chemical, and electric component indastries. 
Table 3

Time Series Analysis of Log RQD

642 Firms

\begin{tabular}{lcc} 
Lag & Antocorre1ations & $\begin{array}{c}\text { Partial } \\
\text { Antocorrelations }\end{array}$ \\
\hline 0 & 1.0 & \\
1 & $.986(.056)$ & $.998(.002)$ \\
2 & $.976(.056)$ & $.048(.034)$ \\
3 & $.968(.056)$ & $-.005(.034)$ \\
4 & $.963(.058)$ & $.016(.034)$ \\
5 & $.961(.058)$ & $-.035(.031)$ \\
6 & $.958(.058)$ & $-.004(.032)$ \\
7 & $.954(.058)$ & $.038(.123)$ \\
\hline
\end{tabular}

Equation

(1)

(2)

(3)

(4)

(5)

\begin{tabular}{|c|c|c|c|c|c|}
\hline $\log R_{-1}$ & $.999(.002)$ & $.934(.039)$ & $.934(.039)$ & $.920(.040)$ & $.922(.040)$ \\
\hline $\log R_{-2}$ & & $.068(.039)$ & $.073(.054)$ & $.058(.040)$ & $.059(.040)$ \\
\hline $\log _{-3}$ & & & $-.005(.034)$ & & \\
\hline $\log P_{0}$ & & & & $.028(.009)$ & \\
\hline $\log _{-1}$ & & & & $.004(.011)$ & $.017(.009)$ \\
\hline $\log _{-2}$ & & & {$[-$.} & $08) .004(.00$ & \\
\hline
\end{tabular}


Table 4

Estimates of the Patent Equation

642 Firms for 1975-1979

Equation

Variable
(1)

Nonlinear

(2)

least squares
(3)

Negative

binomial
$.12(.30)$

$.07(.21)$

$-.08(.15)$

$.28(.24)$

$.39(.09)$

$.23(.07)$

og book plant in 1972

Dummy (sci. sector)

8

Log likelihood

$.36(.23)$
Poisson

$.28(.03)$

$.21(.07)$

$.30(.10)$

$.03(.04) \quad .07(.10)$

$.04(.08)$

$-.001(.036) \quad .08(.10)$

$.06(.08)$

$.28(.03) \quad .16(.07)$

$.25(.11)$

.58

.52

$.66(.05)$

$.21(.004)$

$.14(.013)$

$.19(.04)$

$.30(.01)$

$.28(.03)$

$.21(.11)$

$.051(.001)$

$280,034 . \quad 297,016$.

Notes:

1. All equations have a separate intercept for each year.

2. Standard errors for NLS and GMT are "robust" estimates computed by generalized Bicker-White-Chamberlain formula. 
Table 5

Estimates of the Patent Equation

346 Firms

Equation

(1)

(2)

(3)

Time period

1975-1979

1975-1979

1977-1979

$\log R_{0}$

$.16(.16)$

$.19(.16)$

$.34(.23)$

Log $R_{-1}$

$-.02(.10)$

$-.07(.10)$

$-.30(.18)$

$\log _{-2}$

$.07(.10)$

$.07(.10)$

$.09(.19)$

$\log _{-3}$

$.36(.18)$

$.06(.09)$

$.02(.13)$

Log $R_{-4}$

$.16(.08)$

$.24(.17)$

$\log _{-5}$

$.17(.12) \quad-.01(.16)$

Log $R_{-6}$

$.10(.12)$

Log R-7

$.10(.12)$

Sum $\log R$

$.57(.07)$

$.59(.07)$

$.57(.07)$

Log book plant

$.22(.05)$

$.20(.06)$

$.22(.06)$

in 1972

Dammy (sci.

$.30(.13)$

$.30(.13)$

$.30(.13)$ sector)

The estimation method is GMT, with separate intercepts for each year, and robust standard errors. 
Table 6

Estimates with Firm Effects

$\begin{array}{cc}\text { Conditional } & \text { GMT with } \\ \text { Negative Binomial } & \text { Correlated Effects }\end{array}$

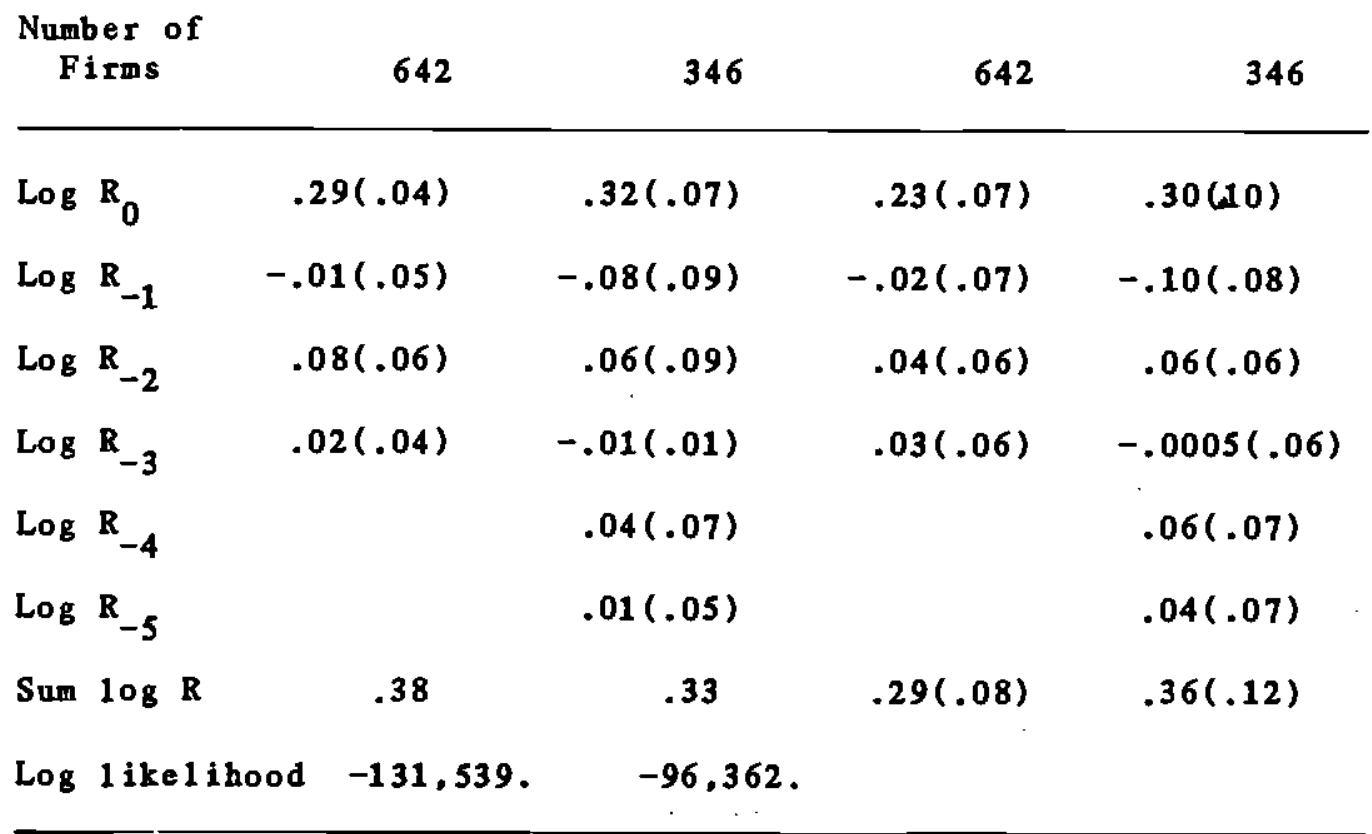

A11 equations contain time dumies. 
Table 7

GMT Estimates Assuming AR1 for RoD

\begin{tabular}{|c|c|c|}
\hline $\begin{array}{l}\text { Number of Firms } \\
\text { Years }\end{array}$ & $\begin{array}{c}642 \\
1972-1979\end{array}$ & $\begin{array}{c}346 \\
1970-1979\end{array}$ \\
\hline $\log R_{0}$ & $.33(.09)$ & $.26(.09)$ \\
\hline $\log R_{-1}$ & $.03(.06)$ & $.04(.04)$ \\
\hline $\log _{-2}$ & $.05(.06)$ & $.01(.04)$ \\
\hline $\log R_{-3}$ & $-.03(.06)$ & $-.03(.05)$ \\
\hline $\log R_{-4}$ & $.11(.08)$ & $.09(.06)$ \\
\hline $\log _{-5}$ & $-.08(.10)$ & $-.04(.06)$ \\
\hline $\log _{-6}$ & $.001(.19)$ & $.05(.08)$ \\
\hline $\log R_{-7}$ & & $.17(.12)$ \\
\hline $\log _{-8}$ & & $-.27(.14)$ \\
\hline Sum $\log R$ & $.41(.24)$ & $.29(.19)$ \\
\hline $\begin{array}{l}\text { Log book plant } \\
\text { in } 1972\end{array}$ & $.18(.04)$ & $.20(.05)$ \\
\hline $\begin{array}{c}\text { Dumay (sci. } \\
\text { sector) }\end{array}$ & $.20(.10)$ & $.27(.12)$ \\
\hline
\end{tabular}


This is a revised version of NBER Working Paper \#1227, prepared for the Conference on Quantative Studies of ReD in Industry, Paris, September 9-10, 1983, held under the auspices of the Ecole Nationale de 1a Statistique et de l'Administration Economique and the National Bareau of Economic Research. We are grateful for helpful comments by the participants in that conference, especially by our discussants, Christian Gourierour and Paul Stoneman, and by Mark Schankerman. This research was supported by the National Science Foundation (PRA 81-08635) and the National Bureau of Economic Research Program on Productivity and Technical Change. Elizabeth S. Laderman provided ertremely able research assistance.

1. Ideally we would like to perform this test also in the other direction using patents on 1 agged patents and RqD, bat there are difficulties in performing a comparable test due to the discrete nature of the dependent variable already alladed to.

2. Another way to understand what the different estimators are doing is to eramine the first order conditions (again suppressing the $t$ subscript and writing $e_{i}$ for $\left.y_{i}-\operatorname{erp}\left(x_{i} \beta\right)\right)$ :

$\begin{array}{lll}\text { NLLS: } & \sum_{i} \exp \left(x_{i} \beta\right) & e_{i} x_{i}=0 \\ \text { Poisson: } & \sum^{i} 1 & e_{i} x_{i}=0 \\ \text { Negative binomial : } & \sum^{i}\left(1+\eta{ }^{2} \exp \left(x_{i} \beta\right)\right)^{-1} e_{i} x_{i}=0 \\ \text { GMT: } & \sum_{i} \frac{\exp \left(x_{i} \beta\right)}{\hat{y}_{i}+\eta^{2} \hat{y}_{i}^{2}} & e_{i} x_{i}=0\end{array}$

Note that the first order condition which we show for the negative ${ }_{2}$ binomial model is conditional on the choice of $\eta^{2}$. Since $\eta^{2}$ is being estimated simaltaneousiy this is not the full set of first order conditions for the problem; we merely inglude it for illustrative purposes. Joint estimation of $\eta^{2}$ is precisely what makes this estimator inconsistent when the distribution is not negative binomis, although the other three estimators remain consistent in this case since they are al1 version of weightod least squares.

Displaying the first order conditions in this way reveals that the estimators only differ in their choice of weights, al though 
NLLS and GMT are minimum distance estimators, and Poisson and negative binomial are marimum likelihood estimators. They can be ranked by the weight which they give to firms with larger $X$ 's, 
Bhargava, A. and D. Sargan. 1983. "Estimating Dynamic Random Effects Mode1s from Pane1 Data Covering Short Time Periods." Econometrica 51: $1635-1660$.

Bound, J.. C. Cummins, Z. Griliches, B. H. Ha11, and A. Jaffe. 1982 . "Who Does RqD and Who Patents?". Nationa 1 Burean of Economic Research Working Paper \#908, in R D, Patents, and Prodnctivity, 1984 , Z. Griliches (ed.): 21-54. Chicago: University of Chicago Press, 1984.

Chamber1ain, Gary. 1982. "Mn1tivariate Regression Mode1s for Pane1 Data," Jonrna 1 of Econometrics (18)1: 5-46. . 1978. "Omitted Variable Bias in Panel Data: Estimating the Returns to Schooling." Annales de 1'Insee, \#30-31: 49-82.

Cummins, C., B. H. Ha11, and E. Laderman. 1983. "The Rot Master File: Documentation." Unpub1ished.

Eicker, F. 1967, "Limit Theorems for Regressions with Unequal and Dependent Errors, in Proceedings of the Ffith Berkeley Symposium on Mathematical Statistics and Probability, Vo1. 1. Berke1ey: Oniversity of Ca1ifornia.

Gourieroux, C., A. Monfort, and A. Trognon. 1984. "Psendo Maximum Like1ihood Methods: Application to Poisson Mode1s," Econometrica 52: 701-720.

Hansman, J. A., B. H. Ha11, and Z. Griliches, 1984, "Econometric Mode1s for Connt Data with an Application to the Patents R\&D Relationship." Econometrica 52: 909-938.

Leamer, Edward E. 1978. Specification Searches: Ad Hoc Inference with Nonexperimenta1 Data, New York: John Wiley and Sons, Inc.

MaCurdy. T. 1981. "Time Series Mode1s Applied to Pane1 Data." Mimeo, Stanford University.

Mansfie1d, E. 1968. Industrial Research and Technological Innovation. New York: W. W. Norton. - 1972. Research and Innovation in the Modern Corporation. New York: W. W. Norton.

Pakes, Arie1. 1982. "Patents, R\&D, and the Stock Merket Rate of Return," Nationa 1 Bnreau of Economic Research Forking Paper \#786. . 1984. "The Option Valne of Patents", mimeo, Hebrew University, Jernsalem. 
Pakes, A, and Z. Griliches. 1980. "Patents and Red at the Firm Leve1: A First Look," National Bureau of Economic Research Forking Paper \#561, in R D, Patents, and Productivity, 1984, Z. Griliches (ed.): 55-72. Chicago: University of Chicago Press.

- 1984. "Estimating Distributed Lags in Short

Pane1s with an Application to the Specification of Depreciation Patterns and Capital Stock Constructs." Review of Economic Studies LI (2): 243-262.

Schankerman. M. and A. Pakes. 1984. "The Rate of Obsolescence and the Distribution of Patent Values: Some Evidence from Enropean Patent Renewa 1s," Revue Economigue. Paris: ENSAE.

Stoneman, Pan1. 1983. "Patents and R\&D: Searching for a Lag Structure Comment." Proceedings of the Conference on Quantitative Studies of Research and Development in Industry. Paris: ENSAE.

Taylor, C. T. and A. Silberston. 1973. The Economic Impact of the Patent System. Cambridge: The Oniversity Press.

White. Halbert. 1982. "Instrumental Variables Regression with Independent Observations," Econometrica 50: 483-500. - 1980. "Nonlinear Regression on Cross-Section Data," Econometrica 48 : 721-746. 